\title{
Virtual team effectiveness: a proposed research agenda
}

\author{
Stacie Furst, Richard Blackburn* \& Benson Rosen ${ }^{\dagger}$ \\ PhD Student, Organizational Behavior, Kenan-Flagler Business School, University of North \\ Carolina at Chapel Hill, McColl Building, CB3490, Chapel Hill, NC 27599-3490, USA, email: \\ fursts@icarus.bschool.unc.edu, *Dick_Blackburn@unc.edu and \\ ${ }_{\dagger}^{\dagger}$ Rosenb@icarus.bschool.unc.edu
}

\begin{abstract}
Contemporary competitive demands have forced many organizations to increase levels of flexibility and adaptability in their operations. A growing number of such organizations have explored the virtual environment as one means of achieving increased responsiveness. In particular, the use of virtual teams appears to be on the increase. However, the increased use of virtual teams has not been accompanied by concomitant research efforts to understand better the socialpsychological contributors to effective virtual teams. In this paper, we use a model of group effectiveness to propose a possible research agenda examining sources of virtual team effectiveness. Although much of this model offers insights relevant to the virtual environment, differences between groups and teams and between colocated and virtual environments suggest that modifications and additions to this model may be necessary. We offer a set of research propositions to advance future research on effective virtual teams beyond anecdote and description. Implications of this research agenda for managers of virtual teams and human resource professionals are also discussed.
\end{abstract}

Keywords: Team effectiveness, virtual teams

\section{INTRODUCTION}

Today's global economy requires many organizations to co-ordinate work across a variety of intra- and interorganizational boundaries (Armstrong \& Cole, 1995; Lipnack \& Stamps, 1997). Using new technology to work 'better, faster, cheaper, and smarter', many businesses are finding that virtual teams can bridge these boundaries and provide a considerable competitive advantage (Lipnack \& Stamps, 1997; Townsend et al., 1998). In particular, virtual teams allow organizations to improve efficiency and productivity, procure expert knowledge from internal and external sources, and transfer 'best practice' information nearly instantaneously (Huber, 1990).

Despite a growing enthusiasm for teams, little empirical research exists that explores the 
dynamics inherent in the virtual work environment (Watson-Fritz et al., 1998). Models that could be used to understand better team development and effectiveness have been limited to those based on the traditional co-located group perspective. Although some comprehensive case studies exist documenting the development of virtual teams (O'Hara-Devereaux \& Johansen, 1994; Lipnack \& Stamps, 1997), theory development and empirical research are needed to help managers better understand and respond to the challenges that virtual teams face. The purpose of this paper is to propose a set of research questions to guide this process.

To ensure clarity in the following discussion, it is important to provide definitions for important terms that we will use in this paper. We will define groups as collections of individuals whose contributions to a product or a process are additive and can be collated and presented by a group manager as the result of group effort. Performance evaluation and accountability for a group will occur at the individual rather than the collective level. We will define teams as collections of individuals who interact more extensively than group members to produce a deliverable, who are evaluated based on the team outcome, and who are accountable as a team (instead of or in addition to individual accountability) for team outcomes (Sundstrom et al., 1990).

Co-located collectivities are those groups or teams whose members are within close proximity of each other and for whom the dominant mode of communication is face-to-face. Members of co-located groups or teams typically work in the same physical location or come together regularly and frequently to meet in the same location.

Virtual collectivities refer to those 'collectivities of individuals geographically and/or organizationally dispersed ... who are assembled using a combination of telecommunications and information technologies to accomplish an organizational task' (Townsend et al., 1998). We distinguish virtual groups from virtual teams in the same way we distinguished groups from teams above. Thus, virtual groups could include employees involved in telecommuting or teleworking, such that most of their interactions are with a manager, and group outputs accrue as a function of the compilation of information by a manager. On the contrary, virtual teams would use a larger array of communications tools because team outputs are a function of more intensive interactions with other team members.

The genesis for much of the research about work in a virtual environment comes from the information technology and information management areas under the general umbrella of computer-mediated communication (CMC). The work of McGrath (1991) and Sproull \& Kiesler (1986) are representative of efforts in this area. There have also been forays by organizational researchers into these interest areas. For instance, Hill et al. (1998) investigated the impacts of operating from a virtual (home) office on work and work/life balance. The focus of these research efforts has been on virtual groups.

Our review of the organizational literature suggests that most of the extant research on virtual teams has been anecdotal and descriptive. For examples, see Lipnack \& Stamps (1997) and Armstrong \& Cole (1995). We have found little in the way of systematic, empirical research into what contributes to the success of virtual teams. For two exceptions, see Jarvenpaa et al. (1998) and Warkentin et al. (1997). Therefore, the basic research question behind this paper concerns what has been or should be the nature of research into the causes of effective virtual teams. 
There are at least two possible explanations for this dearth of empirical research on virtual teams, one temporal and one theoretical. First, virtual teams are a relatively recent phenomenon, and the initial investigations of new organizational issues have typically been descriptive efforts. Second, it may be that managers and academicians do not yet appreciate that working in a virtual environment may require different approaches from working in the traditional organizational environment. Perhaps researchers have not pursued more rigorous investigations of virtual teams on the assumption that previous theory and practice on traditional group processes and outcomes easily generalize to the virtual environment.

This assumption begs empirical testing, however. Perhaps the place to begin such an examination is with Hackman's (1983) model of group effectiveness. Although we considered other models of team processes (e.g. McGrath, 1991; Dennis et al., 1998), we selected Hackman's model for two reasons. First, his model is among the more sophisticated and exhaustive models in terms of variables that might impact group effectiveness. To the extent we can build our discussion on this framework, we have a wealth of possible variables to consider that may (or may not) have similar effects on virtual teams. Second, although Hackman (1983) models group rather than team processes, the emphasis on socio-psychological rather than socio-technical constructs is particularly relevant to our research focus.

Some might argue that by starting from Hackman's model we risk pouring new wine into old bottles. At this stage of the research life cycle in virtual groups, however, we felt it was important to build on what is already known about co-located groups, assess aspects of that work that are generalizable to virtual teams and offer suggestions for areas where generalization seems inappropriate. We will examine the major components of Hackman's model and suggest areas that we feel require additional research when examined from a virtual perspective.

\section{HACKMAN'S MODEL OF GROUP EFFECTIVENESS}

Hackman (1983) has developed a well-known model depicting the variables associated with (co-located) group effectiveness. The model appears in Figure 1. Hackman suggests that group effectiveness is a multidimensional construct consisting of three factors.

1 The degree to which the group's products or services meet the standards of quantity, quality and timeliness of those who receive, review and/or use the output.

2 The degree to which the group's work processes enhance the capability of members to work together interdependently in the future.

3 The degree to which the group's experience contributes to the growth and personal wellbeing of team members (Hackman \& Walton, 1986).

Hackman's emphasis on achieving productive output as well as the social needs of group members is consistent with other models of group effectiveness (McGrath, 1991; Argote \& McGrath, 1993). We think that team efficacy and positive work experiences for team members will continue to be important indicators of virtual team effectiveness. 


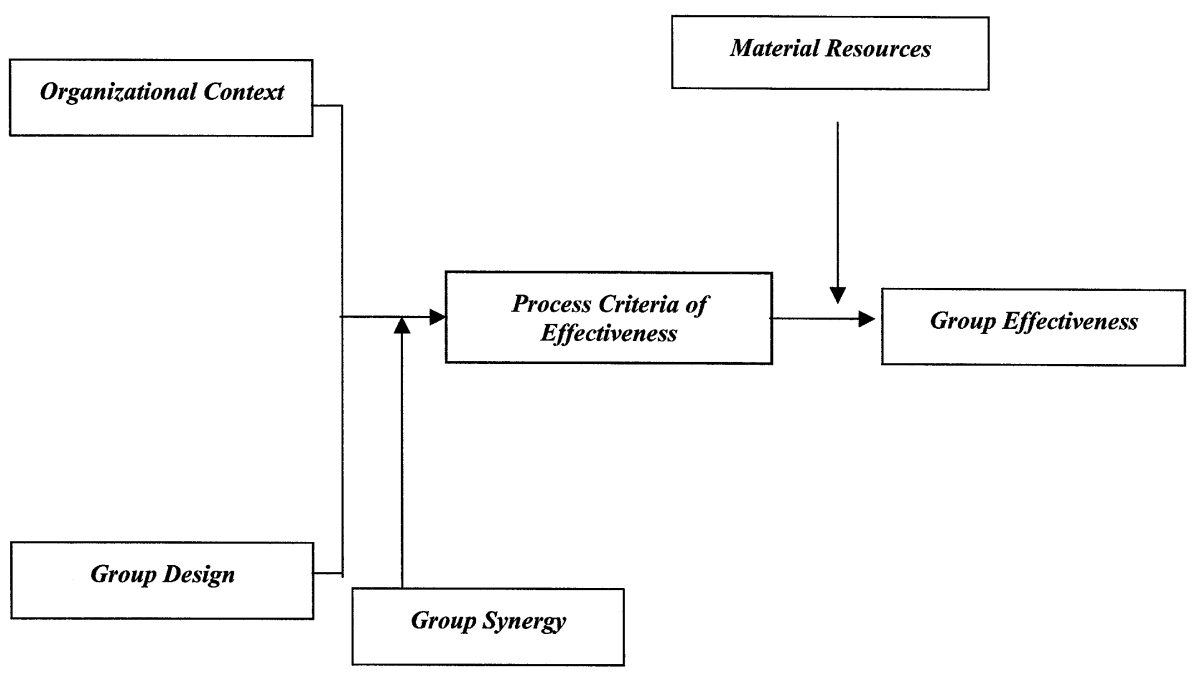

Figure 1. Model of group effectiveness (Hackman, 1983).

It might be appropriate, however, to ask whether a positive work experience in a co-located group will necessarily be the same in a virtual team. Should we assume, without further investigation, that task completion will be equally satisfying and fulfilling in the virtual environment as it might be in the co-located environment? Existing research indicates that team members' satisfaction with the process may depend upon the type of communication technology used. Researchers suggest that the richness of the communication technology media may reduce many of the problems associated with virtual team interaction (Daft \& Lengel, 1986; Dennis \& Kinney, 1998). Regardless, organizations wishing to recognize virtual team successes will be challenged to find ways to celebrate virtual team 'wins' with the same exuberance demonstrated by co-located teams. How do you dump Gatorade on virtual team leaders/ members in the virtual environment?

This also suggests that more research is needed to examine the impact that virtual team successes or failures have on the psychological well-being and productivity of team members. Just as it is difficult to pat team members on the back after a virtual team success, it may be even more difficult to throw a sympathetic arm around a virtual team member's shoulder after a virtual team failure.

Hackman's (1983) three outcome dimensions have generated a number of important dependent variables used in group-related research since Hackman introduced his model. However, we believe that developments in the organizational sciences suggest that at least one more dimension should be added to determine virtual team effectiveness. Recent discussions of learning organizations (Senge, 1990; Huber, 1991; Garvin, 1993) and the knowledge management (Nonaka, 1991; Davenport \& Prusak, 1997) associated with such organizations suggest that these outcomes might yield an important effectiveness dimension. Because of space limitations, we cannot provide a more detailed discussion of this literature. We refer 
interested readers to the following for a more comprehensive examination of organizational learning (Senge, 1990; Argyris, 1999), knowledge management (Leonard-Barton, 1995; Davenport \& Prusak, 1997) and organizational memory (Walsh \& Ungson, 1991).

As knowledge management becomes increasingly important for competitive advantage (Bierly \& Chakrabarti, 1996; Grant, 1996; Mowery et al., 1996), the effective use of virtual teams may become a prerequisite for organizations to compete successfully. The knowledge-based view of the firm asserts that a firm's ability to create and disseminate knowledge in a timely fashion can provide a competitive advantage, particularly in rapidly changing environments requiring timely innovation and response (Grant, 1996). Although the life span of a virtual team may be limited to a particular project's duration, the 'learning' that takes place through the team process may create organizational benefits in two ways. First, virtual teams enable employees to expand their social networks within organizations. Additionally, the work methods of virtual teams can become an important part of the organization's knowledge repository or 'organizational memory' (Walsh \& Ungson, 1991; Lewis, 1998). Electronic exchanges can be archived providing future teams with information about team problems confronted and team solutions generated in the past.

Given these arguments, we suggest that with respect to a model of virtual team effectiveness, we need to add a fourth effectiveness dimension to Hackman's model. In addition to the three dimensions he proposed, we suggest that virtual teams will also be effective as a function of the following.

4 The degree to which the team's process and outcomes can be captured electronically, stored and retrieved as needed to contribute to increased levels of organizational knowledge and learning for future teams.

Hackman's model predicts that group effectiveness is a function of five general categories of variables: organizational context, group design, group synergy, group process and group material resources (Hackman, 1983; Hackman \& Walton, 1986). We will discuss each of these factors in turn as they apply to co-located teams and develop a series of research questions. Answers to these questions should provide an improved understanding of teamwork in a virtual environment.

\section{Organizational context}

As this discussion is of issues that occur at the mesolevel in organizations, we make some assumptions about the impact of macrolevel variables on the success of groups or teams, colocated or virtual. We assume that an organization's strategy, structure, size and core technology are supportive of virtual teams. More particularly, the context variables discussed below will probably have positive or negative effects on virtual team effectiveness, depending on the way these systems are designed.

For groups to perform effectively, organizations must provide the right context, including the appropriate physical, financial and social support. Examples of these support systems might include: 
- evaluation and compensation systems that encourage competent task- and group-related behaviours;

- training and development programmes that provide the appropriate task and group process skills;

- information systems that provide relevant, accurate and timely information for the group; and

- a corporate culture that encourages and supports collective activities (Dennis et al., 1988).

As organizations embrace virtual teams, to what extent do these issues become more or less relevant? For instance, as the virtual environment allows organizations to build teams with members from various corporate functions and/or locations, new evaluation systems may be needed to assess both individual contributions to the team and the nature of team performance as a whole. Virtual team members may attempt to overcompensate for the reduced visibility of their work, producing more reports or paperwork than they would in a non-virtual setting. To the extent that this occurs, different modes of evaluation may be needed. Virtual teams might make greater use of peer-based evaluation systems during the team project, particularly if managers have little contact with team members. Also, performance dimensions such as knowledge management, creative use of communications technology and consensus building may supplement traditional evaluation criteria.

Similarly, compensation systems may need to be redesigned to ensure that a substantial portion of the compensation package is based on team outcomes and team-member contributions to those outcomes. Evaluation and compensation challenges will only be greater when teams operate across country and cultural boundaries. Differing cultural values and behavioural norms may hinder the effectiveness of a corporate-wide reward structure (Armstrong \& Cole, 1995; Townsend et al., 1998). For example, in their study of virtual teams within a multinational computer corporation, Armstrong \& Cole (1995) observed that the company's recognition and reward programmes, designed for US engineers, did not always fit the cultures of subgroups in other countries.

Training and development and information system support are context variables that must change as the impact of the virtual environment increases. Virtual teams will be successful to the extent that appropriate hardware and software are available to team members. However, which hardware and software will be appropriate for which virtual team tasks is a significant issue. As technology further enables virtual teams, training team members in the use of the new hardware and software is an important first step, for it is often through this technology that team members manage the team development process. Training on team process development will be crucial.

Finally, the issue of cultural support for working in the virtual environment is an important one. In many organizations, there is a perceived expectation that being present at work is an important aspect of one's performance. 'Being there' and 'being seen' are viewed as evidence of commitment to the organization. A corporate culture that assumes 'out of sight, out of mind' suggests that a virtual experience may not be seen as a valuable career development step. In contrast, in cultures where 'absence makes the heart grow fonder', virtual team membership would probably not be detrimental to one's career. 
These context issues must collectively support virtual teams, if such teams are to be successful. Changing one of these factors without considering the possible systemic effects of changes in the other factors is a recipe for virtual disaster. For example, changing hardware and/or software to encourage the formation of virtual teams without providing training and development for those using the new tools will result in frustrated team members and lower team performance. Similar systemic relationships among these context elements must be appreciated. These issues suggest the following research questions.

- How must organizational performance evaluation and compensation systems change to support virtual teams?

- How can team-member contributions to team outcomes best be measured, evaluated and rewarded?

- How can team outcomes themselves best be measured, evaluated and rewarded?

- What should be the role of the information technology, human resource and training function in co-ordinating and supplying the training necessary to use new team-based hardware and software to facilitate team-based virtual environments?

- In what types of corporate cultures are virtual teams more likely to flourish?

- What types of cultural changes will be necessary for organizations to successfully implement virtual teams?

- Which way does the causal arrow point? Will the use of a few virtual teams enable significant cultural change or will extant cultures continue to facilitate or inhibit virtual team success?

\section{Group design}

A second factor that influences group effectiveness is the degree to which the group design facilitates competent group work. Design elements include the appropriateness of the assigned task, the composition of the group and the development of group norms about performance processes (Hackman, 1983). Obviously, many tasks do not require the formation of a group (Vroom \& Yetton, 1973). According to Hackman \& Walton (1986), the decision to use groups depends on the extent to which: (1) interdependent activity is necessary for successful task completion; (2) the organization exhibits a 'commitment' compared with a 'control' work force management strategy; and (3) the corporate culture supports group activities. Second, group membership must be appropriate given the assigned task. Groups designing new products will require different types of expertise than groups developing financial control systems. Third, group members need the skills necessary to work in a group setting. Finally, behavioural norms, the informal rules for how work gets done in a group, must support the accomplishment of the group's task. Norms may include punctuality, active participation, constructive feedback and timely responses to task-related assignments. We look at each of these issues individually.

\section{Team structure}

Early research on virtual forms examined the relationship between team tasks and team structures. This research sought to determine whether 'teaming' in general and virtual 'teaming' 
in particular are effective for accomplishing organizational objectives. For example, Huber (1990) suggests that simple electronic communication, such as electronic mail or bulletin board systems, can be used to exchange factual or technical information. However, more advanced technologies, such as videoteleconferencing, may be necessary to communicate complex or socioemotional information. In the absence of those advanced technologies, virtual activities may not be a viable option.

In a comprehensive review of studies on computer-mediated groups, Hollingshead \& McGrath (1995) reported that computer-based groups generated more ideas, exchanged fewer messages and took longer to complete work than did co-located groups. They suggested that computer-mediated groups would be more effective for brainstorming types of activities but less effective for actual problem solving. Gallupe et al. (1991) concurred with this view, attributing the effectiveness of electronic brainstorming to reductions in both production blocking and evaluation apprehension. The use of asynchronous technology allowed more team members to participate and reduced concerns about judgements of individual contributions. However, using a different type of technology, such as teleconferencing, has been shown to reduce the time delays associated with decision making in computer-mediated groups, suggesting that - given the appropriate technology - virtual decision making may also be effective (Guzzo \& Dickson, 1996). These conflicting results underscore the importance of assessing the technology-task fit as a key determinant of team structure.

Another potential determinant of group structure is the nature of the task. McGrath (1991) distinguished four types of tasks: generating ideas or plans, choosing among alternatives, negotiating conflicts and executing activities. From the virtual perspective, it is likely that the first two types may be more amenable to successful virtual accomplishment than the last two. As Goodman et al. (1987) suggest, idea generation and alternative selection may be facilitated in an electronic environment. On the contrary, conflict management cannot be easily practised within a virtual environment. Similarly, the actual execution of activities would probably not be in the purview of the virtual group. More likely, the outcome of virtual efforts are reports, product ideas or plans that become the basis for execution by others (Lipnack \& Stamp, 1997). To the extent that the virtual team's task is more complex and/or requires more interdependent activities, more research is needed to understand how these interactions can be facilitated virtually. These issues suggest the importance of the following research questions.

- What are the characteristics of organizational tasks that make these tasks more or less appropriate for assignment to virtual teams?

- Under what task requirements, if any, are co-located group hierarchical and/or communication structures equally appropriate in the virtual environment?

- Which task characteristics require which hardware and software technologies for their successful accomplishment by virtual teams?

\section{Group composition}

In addition to the functional knowledge needed to build effective virtual teams, team members must possess the appropriate knowledge, skills and abilities (KSAs) to perform successfully in 
the virtual setting. In a recent review of this literature, Stevens \& Campion (1994) identified 14 KSAs associated with effective group member performance and classified these into the five areas listed below (with a representative KSA).

1 Conflict resolution. ('To recognize and encourage desirable, but discourage undesirable, team conflict.')

2 Collaborative problem solving. ('To recognize the obstacles to collaborative group problem solving and to implement appropriate corrective actions.')

3 Communication. ('To listen non-evaluatively and to appropriately use active listening techniques.')

4 Goal setting and performance management. ('To establish specific, challenging and accepted team goals.')

5 Planning and task co-ordination. ('To co-ordinate and synchronize activities, information and task interdependencies between team members.' Stevens \& Campion, 1994, p. 505)

Although many of these KSAs are necessary for successful virtual team membership, in our estimation this list is neither totally transferable nor complete in the virtual environment. For instance, although it is desirable to recognize and encourage functional conflict in virtual teams, how does one go about doing this? Given the text-based demands of many interactive communication systems, skills required to diagnose conflicts on-line may be quite different from those required to diagnose conflicts off-line. A 'huff' and a cold-shoulder in real-time may be more indicative of a potential conflict than a slow or terse reply to an e-mail message. In fact, a significant body of research relating to computer-mediated communication suggests that as the level of interdependence and socioemotional communication increases on a team task, the performance of computer-based teams in comparison to co-located teams declines (see, Bordia, 1997).

Similarly, listening non-evaluatively and using active listening techniques may be appropriate for co-located groups, but what is the matching KSA in the text-based virtual environment? Studies indicate that, in the absence of a social context, members of computer-mediated teams may pay more attention to the actual information exchanged, but may be biased towards more recent information (Siegel et al., 1986). Perhaps 'listening' must be redefined for virtual purposes.

Finally, there are no KSAs in the Stevens \& Campion (1994) list aimed at selecting the appropriate hardware and software, given the nature of the virtual task, or for using the various types of hardware and software to help the virtual team function successfully.

Thus, research is needed to determine to what extent these KSAs can be retained and/or must be modified. In addition, we need to determine whether new KSAs exist that would contribute to virtual team effectiveness. The implications of this research gap are profound for managers. Without such knowledge, recruitment, selection and training systems may not find and/or develop employees best suited for virtual team membership. This discussion suggests that the following research questions deserve further attention.

- What team-member KSAs are necessary for effective virtual team performance?

- How should recruitment, selection and training systems be changed, if at all, to ensure that employees have the requisite KSAs for effective virtual team membership? 


\section{Team norms}

The development and enforcement of norms in virtual teams presents organizations with unique challenges. First, group research indicates that an important antecedent of group norms is the opportunity for new group members to observe how other group members interact in the colocated setting (Markham \& McKee, 1995). In many virtual contexts, it is nearly impossible for virtual team members to actually observe those behaviours used to establish informal rules or norms (Finholt \& Sproull, 1990). Thus, new approaches may be necessary in virtual settings to expedite the formation of team norms.

Popular discussions of virtual teams (Lipnack \& Stamps, 1997) suggest the need for at least one early face-to-face meeting of virtual team members to begin the norm development process. Whereas some norm development and reinforcement can occur on-line, it may be necessary for team leaders to use off-line communications to strengthen group norms and/or to sanction inappropriate virtual norm violations. For example, a manager or team leader may observe that a virtual team member has not 'participated' in the team effort for an extended period of time. Subtle on-line queries may need to be followed by progressively stronger off-line demands for appropriate behaviours.

Another challenge in the development of virtual norms arises with the presence of cultural differences among team members. In multinational organizations, teams will probably consist of members from different countries, with differing cultural values making norm development difficult. Team behaviours viewed as acceptable in one culture may not be viewed as such in another culture (Armstrong \& Cole, 1995; Kirkman \& Shapiro, 1997). Several studies in the groups literature indicate that groups comprising members from what might be termed 'collectivistic' cultures (Hofstede, 1980; Wagner, 1995), such as Japan and the Netherlands, may outperform groups comprising individuals from individualistic cultures, such as the United States (Latane, 1986; Earley, 1993; Wagner, 1995). But when team membership includes representatives of both individualist and collectivist cultures, definitions of acceptable behaviours may differ considerably and be difficult to resolve. Armstrong \& Cole (1995) reported that several US managers characterized European engineers' relations with management as more formal and hierarchical than they were accustomed to with US engineers, who were more verbally confrontational with objectives and questions. How might teams working in the virtual environment best manage these cultural differences as they develop and reinforce team norms? These issues raise a variety of potential research questions.

- Are norms a more or less important consideration in the virtual team environment than they are with co-located teams?

- How do norms develop in virtual teams?

- How can norms be effectively reinforced and/or sanctioned in virtual teams?

- Because virtual teams function within a restricted communications venue, will more or fewer norms develop around appropriate virtual team behaviours?

- What types of behaviours might those norms proscribe?

- To what extent will virtual team norms transcend country and cultural borders, if at all?

- Will differences in behaviour attributable to culture affect the acceptance of norms in the 
virtual environment to the same extent that such differences affect norm acceptance in the colocated environment?

- To what extent will virtual norms influence the cohesiveness of virtual teams, if at all?

- To what extent is cohesiveness even an appropriate concept to consider in the virtual environment?

- If it is, then how can team cohesiveness best be managed?

- What are the most appropriate processes to overcome the cultural barriers that may reduce virtual team effectiveness?

\section{Group synergy}

Hackman's third category of factors that influence group effectiveness is group synergy. These variables moderate the impact that context and design variables have on that category of variables Hackman labels 'Process Criteria of Effectiveness.' Group synergy factors reflect the ways in which group members interact to maximize important group outcomes, such as the diversity of ideas generated (Nemeth, 1993), member involvement (Lawler, 1986), and increased group efficiency and productivity (Hammer \& Champy, 1993). Researchers have identified several potential antecedents to synergistic behaviour in work groups, including establishing a group identity that encourages group members to put group goals before individual goals (Gaertner et al., 1989), building trust among group members (Mayer et al., 1995) and generating co-operation among heterogeneous group members (Tsui et al., 1992; Nemeth, 1993; Watson et al., 1993).

\section{Building team identity}

Team identity is defined as the acceptance of team goals and collective commitment to put team goals ahead of individual goals (Gaertner et al., 1989). Team identity develops over time as teams clarify goals, set priorities and invest energy towards accomplishing team objectives. Team identity is further enhanced when team members perceive their colleagues to be attractive, capable and of high relative stature (Berger et al., 1986).

Team identity is developed through the establishment of and commitment to team goals and objectives. Research relating to goal setting typically finds a positive relationship between the existence of clear, challenging goals and increased individual (Locke et al., 1981) and group productivity (Pritchard et al., 1988). Clear and agreed upon goals and objectives reduce potential uncertainty regarding performance expectations. Such goals may also challenge team members, giving them a heightened sense of urgency relative to accomplishing team-based objectives (Locke et al., 1981). These goals and objectives should help to build a collective team identity, fostering the co-operative behaviours necessary for effective teams (Yamagishi, 1993). Researchers report that for virtual teams the ability to create, communicate and gain commitment to goals is an important 'first step' towards effective team performance (Lipnack \& Stamps, 1997). Face-to-face interactions between team members (however infrequent) increase member awareness of expected team behaviours as well as an appreciation of team 
interdependencies (Yamagishi, 1993). In the absence of this contact, virtual team members must rely on their collective understanding and commitment to team goals to guide their behaviours.

Several mechanisms might be used to create team identities, including face-to-face orientation sessions and on-line team building and training. These techniques and other more sophisticated socialization efforts sound compelling, but their effectiveness has not been systematically evaluated. We were unable to find any empirical research that examined when and how team formation/socialization processes successfully occur in the absence of substantive face-to-face interactions.

As new members join existing co-located groups, older members have the opportunity to socialize newcomers (Jackson et al., 1992). Socialization may include recounting the group's history, modelling the team's values and mentoring newcomers in adherence to group norms. The socialization of new members contributes to building group identity. Accordingly, research on how this process may occur in virtual teams and how teams develop a sense of team identify could prove quite valuable. Among the issues in need of further study are the following.

- To what extent are the socialization procedures used for co-located group members appropriate for individuals becoming virtual team members?

- To what extent do team goals and objectives guide virtual team behaviour?

- What is the most effective way to establish agreement upon and commitment to team goals in a virtual environment?

Trust

Trust represents an important antecedent of synergistic work group behaviour (Mayer et al., 1995). Trust refers to the likelihood that team members will live up to their colleagues expectations (Mayer et al., 1995; Jarvenpaa et al., 1998). There are two important dimensions of trust: dependable task completion and benevolence towards others (the extent to which others exhibit care and concern for team members and their willingness to assist others beyond what their role may require). Several studies have demonstrated that in the absence of trust, team members reduce their own efforts and withhold co-operation with others (Schnake, 1991; Mayer et al., 1995).

Jarvenpaa et al. (1998) examined how trust develops in virtual groups. Teams of university students worked on computer-mediated problem-solving simulations. Findings indicated that trust was positively related to virtual team productivity. Trust in team-mates' task competence developed in the early stages of the simulation, whereas trust in team-mates' benevolence developed later. The authors concluded that trust is 'pivotal in preventing geographical distance from leading to psychological distance in a global team' (Jarvenpaa et al., 1998, p. 30).

In the context of the computer simulation, Jarvenpaa et al. (1998) also experimented with team-building activities before the start of the project. Surprisingly, these activities did not have a direct effect on trust levels. This raises some interesting questions on the relationship between trust and virtual team performance and the most effective strategies for building 
trust within virtual teams. Yet to be investigated are the specific behaviours of virtual team members (e.g. long periods off-line, terse messages, etc.) that contribute to perceptions of trust or mistrust.

- What are the antecedents of trust in virtual teams, and what are the relative contributions of these antecedents to team trust?

- What are the behaviours engaged in by virtual team members that most frequently engender trust and/or mistrust among the virtual team?

\section{Managing team co-operation and heterogeneity}

As virtual team membership becomes more heterogeneous in response to more complex and varied virtual team tasks, successful management of team co-ordination and co-operation will become increasingly important. Not surprisingly, research shows that team heterogeneity can be either an asset or a liability to team effectiveness (Bettenhausen, 1991; Guzzo \& Dickson, 1996). Heterogeneity refers not only to differing demographic characteristics and cultural norms of team members, but also to their diversity of functional roles (Dougherty, 1992) and the tenure of virtual team members (Jackson et al., 1992). As suggested above, heterogeneity is likely to be high in a virtual team because team members are more likely to represent different cultures, locations and functions. Conflicts can arise as various team members struggle to see outside their own 'thought-worlds' (Dougherty, 1992) and to overcome language barriers. The virtual environment may ameliorate some of the adverse effects of heterogeneity by limiting the presence of social cues that trigger categorization.

For example, there is some evidence that status inequalities are attenuated in computermediated groups, presumably because less attention is devoted to social categorization factors (see Bordia, 1997). However, there is also evidence that because virtual team members are more removed from the 'social context' they are more likely to engage in uninhibited behaviour (for example, impolite or inappropriate remarks made on electronic mail), thus increasing the chance of conflict (see Bordia, 1997). Given these competing findings, more research is needed that directly addresses the issue of co-operation in heterogeneous virtual teams.

Similarly, technology capable of translating text into other languages is available that enables virtual team members to communicate in their native tongues, overcoming language barriers and speeding information sharing. However, the risk that some subtleties in such communications will 'get lost in translation' will continue to be a problem. As new technologies develop to facilitate communication among culturally diverse virtual teams, new research questions follow closely behind.

- To what extent does the nature of the technology used in the virtual team environment facilitate or mitigate the potential negative effects of increasing team member heterogeneity?

- What mechanisms are available or can be developed to assist virtual teams to resolve conflicts and overcome process losses that might be associated with increased member heterogeneity? 


\section{Process losses}

Along with the opportunities for synergies to develop as a result of team formation, the likelihood for process losses to occur also exists. We posit that an inverse relationship between the level of visual contact between team members and certain process losses, such as creativity, may exist. For instance, communication that is less rich is least affected by process losses. Process losses diminish a group's performance potential as a function of such problems as social loafing, freeriding, groupthink and/or groupshifts. We briefly consider the potential effects that the virtual environment might have on these problems.

\section{Free-riding/social loafing}

Latane et al., (1979) found that individuals tend to perform at lower levels when part of a group than when they are expected to complete a task on their own. They labelled this effect 'social loafing' and have since discovered that the phenomenon is not limited to face-to-face groups. Free-riding, a construct similar to social loafing, is a choice individuals sometimes make to avoid co-operating in the pursuit of rewards to be shared by the members of a group (Wagner, 1995). Research suggests that free-riding and social loafing are analogous in that both grow out of the same choice to withhold co-operative effort from group endeavours, and both have the same potential to jeopardize group performance and well-being (Wagner, 1995).

Researchers have identified several conditions that can increase the potential for group members to engage in social loafing, including increased group size (Latane, 1986; Gallupe et al., 1992), reduced task identifiability (Guzzo, 1986; George, 1992), reduced intrinsic involvement (George, 1992) and reduced feelings of shared responsibility (Wagner, 1995). Many of these findings seem equally applicable to virtual teams.

For instance, Latane et al. (1979) demonstrated that social loafing tends to occur whether or not group members can see one another. Bettenhausen (1991) identified several additional studies that discovered an inverse relationship between individual task identifiability and social loafing. Therefore, in the context of actual work (i.e. time spent doing the virtual work required), virtual team members may perceive that their efforts (or lack thereof) are invisible to other team members. Secondly, the psychology literature is replete with studies demonstrating a negative relationship between worker isolation and feelings of motivation and psychological involvement in a task (Finholt \& Sproull, 1990; Baumeister \& Leary, 1993). These studies show that, in the absence of face-to-face contact, the informal conversations and group interactions that tend to elicit feelings of meaningfulness, belonging and purpose in a group will be absent, reducing intrinsic involvement (Finholt \& Sproull, 1990). Given the inherent isolation associated with virtual team membership, virtual teams may be more likely to experience decreased intrinsic involvement and thus increased social loafing.

Despite the apparent vulnerability to social loafing in virtual teams, no comprehensive empirical tests of these predicted relationships have been conducted. Research is needed to explore what conditions contribute to social loafing or free-riding in virtual teams and what interventions can abate those conditions. 
- Is social loafing/free-riding more or less likely in virtual teams than it is in co-located teams?

- What are the antecedents of social loafing or free-riding in virtual teams?

- What technologies and/or management interventions might be most useful to reduce the likelihood of social loafing or free-riding in virtual teams?

\section{Groupthink and groupshift}

Groupthink and groupshifts represent two forms of potential process losses that can occur during group efforts. The concept of groupthink (Janis, 1982) has been an oft-examined issue regarding possible post hoc explanations for what seem to have been poor decisions (e.g. Bay of Pigs invasion, Challenger shuttle launch). Groupthink arises when group members place more emphasis on maintaining illusions of consensus and cohesiveness than they do on a full and complete airing of possible differences about a particular issue. Evidence suggests that groupthink is most likely to occur when groups are overly cohesive and value mutual attraction more than they value high-quality decisions, when strong group leaders pose their solutions as most appropriate and suppress discussion of solution shortcomings or alternative solutions, and when information contrary to the group's position is not allowed to be brought to the group's attention (Janis, 1982; Whyte, 1989).

The groupshift phenomenon represents the possible differences between the decisions that arise from group discussions and the decisions individual group members might make were they not group members. Although the early research into this event focused on 'risky' shifts (groups tend to make riskier decisions than individuals) (Clark, 1971), more recent investigations have found that some group decisions may involve a conservative shift (groups tend to make more conservative decisions than individuals) (Isenberg, 1986; Paese et al., 1993). In both cases, the general explanation for both results suggests that group discussions tend to exaggerate the initial positions held by group members. Thus, if most of the group members tend to favour a risky decision before the group discussion, then, all else equal, the group's decision will probably be a risky one. Similarly, a conservative bias among group members before discussion will probably lead the group to a more conservative group decision. Research is needed to determine what might be the impact of the virtual team environment on the likelihood of groupthink or either of these groupshifts occurring.

- Is groupthink or groupshift more or less likely in the virtual environment?

- Under what conditions might either occur more or less frequently?

- Is it more or less difficult to present contrary information or to champion a minority opinion in a virtual team context than in a co-located one?

- How does the mode of virtual team interaction (asynchronous compared with synchronous) affect the potential for groupthink or groupshift?

\section{Process criteria of effectiveness}

In Hackman's (1983) model (see Figure 1), the group synergy variables moderate the impact of context and design variables on the 'process criteria of effectiveness.' Whereas the likelihood of 
group synergy is increased by the strength of the psychological connections or 'identity' of group members with group goals, process criteria represent the level of effort, knowledge and skill brought to the team task and the appropriateness of the performance strategies given the nature of the task. In other words, the work processes used by the group should reflect the complexity and level of importance of the work being carried out.

When we think about group process, two group process models come to mind - one traditional and the other contemporary. The traditional model was introduced by Tuckman (1965) and updated by Tuckman \& Jensen (1977) and Maples (1988). The underlying premise of the model is that groups go through relatively discrete stages of development (i.e. forming, storming, norming and performing). Those groups best able to negotiate these developmental stages find their process efforts most effective.

Gersick $(1988,1989)$ proposed a more contemporary consideration of group development: the punctuated equilibrium model. Gersick found that the timing of group formation and the way group work efforts change over time were consistent regardless of the group, the nature of the group's task or the deadline for completing the task. More specifically, Gersick's research suggests that groups experience what might be called a 'mid-life crisis.' For the first half of their allotted time together, groups tend to operate from inertia with little actual focus on the work to be accomplished. Nevertheless and regardless of the amount of time allocated to a group task, at about the halfway point in their schedule groups begin to focus more energy on task accomplishment. These renewed efforts carry the group forward to task completion.

Gersick's work provides some interesting implications for group development. The first meeting of the group is critical because it establishes many of the behavioural patterns, assumptions and norms that will be applied during the first half of the group's time together. It is not unusual to see little concrete action during the first half of a group's life. Reducing the time allocated may speed up the group process, but at the cost of poorer group outcomes. Gersick's $(1988,1989)$ early research on this phenomenon began with co-located groups. What might be the impact of the virtual environment on this punctuated equilibrium approach to understanding team process? For instance, we have discussed already the importance of bringing virtual teams together early in their lives for face-to-face interactions. These meetings are of value for a variety of reasons, and become even more significant if punctuated equilibrium generalizes to the virtual team development process. Are first meetings as important to the mid-point transition in virtual teams as they are in co-located teams? Is the inertia associated with the first phase of group development more or less likely in the virtual team? These questions illustrate the types of enquiries regarding the group process that need to be answered. Other questions that group process issues might pose for future research include the following.

- Do virtual teams go through the same four-stage development process that Tuckman (1965) proposed for co-located teams?

- If so, what technologies or techniques can be used to guide the virtual team through this process and to facilitate development to the performance stage?

- Does the punctuated equilibrium approach apply to virtual teams? 
- For instance, is the inertia associated with the first phase of group development more or less likely in the virtual team?

- Would we find the same mid-point transition?

- Would deadline changes have the same impact?

- How might technologies used by virtual teams affect this model?

\section{Material group resources}

Hackman (1983) asserts that the sufficiency of material group resources (which we interpret to mean non-human group resources) moderates the influence of the process criteria on the overall effectiveness of groups. In particular, a group's ability to identify its resource needs and fill those needs in a timely manner influences its overall effectiveness. From our perspective, material resources include the tools and technology available to and used by a group (and the attendant support personnel necessary to ensure the technology is used to its fullest potential), the time afforded the group to complete its task assignment, the physical space available to the group during its life, and the financial resources available to conduct training or to procure other necessary resources.

The potential impact of these factors on co-located groups should be obvious. Remove sufficient levels of any of these resources and a co-located group will have a difficult time being productive. In particular, in the absence of financial resources, the group may be unable to purchase the necessary technology, find sufficient space in which to operate, or accomplish its task within the time allotted.

From the virtual perspective, financial resources continue to play a significant role. The ability to purchase reliable technologies will influence team effectiveness and member satisfaction with the team process (Huber, 1990; Bettenhausen, 1991). Without sufficient financial resources, appropriate technologies may not be available. The high (though admittedly decreasing) costs of more advanced information technology may limit an organization's ability to link dispersed organization members virtually (Boutellier et al., 1998). In addition, team members working from remote and/or underfunded locations may not have access to the same technologies as other team members constraining team performance. Finally, if the technology fails or team members are not trained in its use, team performance will probably suffer (Goodman, 1986).

Issues of time and space are generally of less concern in the virtual environment. In fact, the reason that many organizations increase the use of virtual teams is exactly to reduce the costs associated with slow development processes or customer response demands (O'HaraDevereaux \& Johansen, 1994; Lipnack \& Stamps, 1997). In addition, the increased costs associated with maintaining office space and/or the increased costs of employee travel make the effective use of virtual teams an attractive option. The space necessary for virtual teams to operate should be merely the sum of the area of the footprints associated with members' computers. This total may be increased by the square footage associated with videoconferencing facilities, but, in any case, the physical space devoted to virtual teams should be far less than that associated with co-located teams. 
- What levels of which types of resources are necessary and/or sufficient for virtual teams to perform effectively?

- Although technology obviously has a substantial impact on the success of virtual teams, what determines the appropriate level of technology support personnel to ensure virtual team effectiveness?

- In terms of balancing the savings from working virtually (for example, reduced travel cost and overhead expenses) with the costs of doing so (for example, investments in technology and training), what is the break-even point at which virtual teams become more cost-effective than co-located teams?

- What is the relationship between each of these resources and virtual team effectiveness?

- Is that relationship necessarily linear?

- Can virtual teams have too many as well as too few material resources?

\section{CONCLUSIONS AND IMPLICATIONS}

Despite the growing popularity of virtual teams, limited empirical research exists that explores the dynamics inherent in the virtual team setting. Whether this lack of research results from the relative 'youthfulness' of the topic or an underestimation of the special challenges facing virtual teams, we believe that additional theory and empirical testing are needed. To that end, we have identified a set of research questions designed to guide a more critical examination of the antecedents of virtual team effectiveness. In general, we concluded that virtual teams are not co-located teams at a distance. Although the two work formats are similar, they are not identical. Using Hackman's model of group effectiveness and extant research on virtual teams, we determined that many previous recommendations for (co-located) group effectiveness remain viable. However, we also identified several research 'gaps' that we believe exist in our understanding of virtual teams. These gaps represent fertile opportunities for future research. It would appear to be time to move beyond description and anecdote and to utilize the strengths of both experimental and survey research designs to fill these gaps in our knowledge about virtual teams.

The implications of this proposed research for managers could be significant. Interviews with several executives who act as both members and leaders of virtual teams revealed that many organizations are not managing their virtual teams any differently from their co-located teams. However, it is apparent from the limited research on virtual groups and computer-mediated communication studies and from discussions with practitioners that significant differences do, in fact, exist between co-located and virtual teams. Managers (and researchers) ignore these differences at their own peril. A systematic approach to empirical research relating to virtual teams should enable managers to understand more completely those conditions that tend to precipitate effective teams. This understanding should enable the development of more appropriate systems for selecting and developing effective team members leading to more effective virtual team performance.

For researchers, we believe a better understanding of the virtual environment suggests 
exciting research questions, the answers to which should yield a more complete understanding of these issues. Hopefully, as these questions are answered, theoretical models for understanding, explaining and controlling virtual team performance will emerge, leading to even more incisive research questions. This initial investigation of virtual teams also suggests that benefits should accrue to both researchers and practitioners by combining ideas from organizational behaviour and human resource management with those from information technology. In the phrase 'virtual teams', we know a great deal about the technical aspects of being virtual. We now need to know more about making the human collectivity, the teams, more virtuous.

\section{REFERENCES}

Argote, L. \& McGrath, J.E. (1993) Group processes in organizations: Continuity and change. In: International Review of Industrial and Organizational Psychology, 8, Cooper, C. \& Robertson, I. (eds), pp. 333-389. John Wiley \& Sons, New York.

Argyris, C. (1999) On Organizational Learning, (2nd edn). Malden, MA: Blackwell Publishers.

Armstrong, D.L. \& Cole, P. (1995) Managing distances and differences in geographically distributed work groups. In: Diversity in Work Teams: Research Paradigms for a Changing Workplace, Jackson, S. \& Ruderman, M. (eds), pp. 187-215. American Psychological Association, Washington, DC.

Baumeister, R.F. \& Leary, M.R. (1993) The need to belong: Desire for interpersonal attachments as a fundamental human motivation. Psychological Bulletin, 117, 497-529.

Berger, J., Webster, M., Ridgeway, C. \& Rosenholtz, S. (1986) Status cues, expectations, and behavior. In: Social Psychology of Groups: a Reader, Lawler, E.J. \& Markovsky, B. (eds), pp. 1-22. JAI Press, Greenwich, CT.

Bettenhausen, K.L. (1991) Five years of group research: What we have learned and what needs to be addressed. Journal of Management, 17, 345-381.

Bierly, P. \& Chakrabarti, A. (1996) Generic knowledge strategies in the U.S. pharmaceuticals industry. Strategic Management Journal of Special Issue on Knowledge and the Firm, 17, 123-135.

Bordia, P. (1997) Face-to-face versus computer-mediated communication: a synthesis of the experimental literature. The Journal of Business Communication, 34, 99120.

Boutellier, R., Gassman, O., Macho, H. \& Roux, M. (1998) Management of dispersed product development teams: The role of information technologies. $R$ and $D$ Management, 28, 13-26.
Clark, R. (1971) Group-induced shift toward risk: A critical appraisal. Psychological Bulletin, 69, 251-270.

Daft, R. \& Lengel, R. (1986) Organizational information requirements, media richness, and structural design. Management Science, 32, 554-572.

Davenport, T. \& Prusak, L. (1997) Working Knowledge: How Organizations Manage What They Know. Harvard Business School Press, Boston.

Dennis, A. \& Kinney, S. (1998) Testing media richness theory in the new media: The effects of cues, feedback and task equivocality. Information Systems Research, 9, 256-274.

Dennis, A.R., George, J.F., Jessup, L.M., Nunamaker, Jr, J.F. \& Vogel, D.R. (1988) Information technology to support electronic meetings. Management Information Systems Quarterly, 22, 591-624.

Dougherty, D. (1992) Interpretive barriers to successful product innovation in large firms. Organization Science, 3, 179-202.

Earley, C.P. (1993) East meets mideast: Further explorations of collectivistic and individualistic work groups. Academy of Management Journal, 36, 319-348.

Finholt, T. \& Sproull, L.S. (1990) Electronic groups at work. Organization Science, 1, 41-61.

Gaertner, S.L., Mann, J., Murrel, A. \& Dovidio, J.F. (1989) Reducing intergroup bias: The benefits of recategorization. Journal of Personality and Social Psychology, 57, 239-249.

Gallupe, R.B., Bastianutti, L.M. \& Cooper, W.H. (1991) Unlocking brainstorms. Journal of Applied Psychology, 76, 137-142.

Gallupe, R.B., Dennis, A.R., Cooper, W.H., Valacich, J.S., Bastianutti, L.M. \& Nunamaker, J.F. (1992) Electronic brainstorming and group size. Academy of Management Journal, 35, 350-369.

Garvin, D. (1993) Building a learning organization. Harvard Business Review, July-August, 78-92. 
George, J.M. (1992) Extrinsic and intrinsic origins of perceived social loafing in organizations. Academy of Management Journal, 35, 191-202.

Gersick, C. (1988) Time and transition in work teams: Toward a new model of group development. Academy of Management Journal, 31, 9-41.

Gersick, C. (1989) Marking time: Predictable transitions in task groups. Academy of Management Journal, 32, 274 309.

Goodman, P.S. (1986) Impact of task and technology on group performance: In. Designing Effective Work Groups, Goodman, P. (ed.), pp. 120-167. Jossey-Bass Publishers, San Francisco.

Goodman, P.S., Ravlin, E. \& Schminke, M. (1987) Understanding groups in organizations. In: Research in Organizational Behavior, vol. 9, Cummings, L. \& Staw, B. (eds), pp. 121-173. JAI Press, Greenwich, CT.

Grant, R. (1996) Toward a knowledge-based theory of the firm. Strategic Management Journal, Special Issue on Knowledge and the Firm, 17, 109-122.

Guzzo, R.A. (1986) Group decision making and group effectiveness in organizations. In: Designing Effective Work Groups, Goodman, P. (ed.), pp. 34-71. JosseyBass Publishers, San Francisco.

Guzzo, R.A. \& Dickson, M.W. (1996) Teams in organizations: Recent research on performance and effectiveness. Annual Review of Psychology, 47, 307-339.

Hackman, J.R. (1983) A Normative Model of Work Team Effectiveness. Yale School of Organization and Management, Research Program on Groups Effectiveness, New Haven, CT.

Hackman, J.R. \& Walton, R.E. (1986) Leading groups in organizations. In: Designing Effective Work Groups, Goodman, P. (ed.), pp. 72-119. Jossey-Bass Publishers, San Francisco.

Hammer, M. \& Champy, J. (1993) Reengineering the Corporation. Harper, New York.

Hill, E., Miller, B., Weiner, S. \& Colihan, J. (1998) Influences of the virtual office on aspects of work and work like balance. Personnel Psychology, 51, 667-683.

Hofstede, G. (1980) Culture's Consequences: International Differences in Work-Related Values. Sage, Beverly Hills, CA.

Hollingshead, A.B. \& McGrath, J.E. (1995) Computerassisted groups: A critical review of the empirical research. In: Team Effectiveness and Decision Making in Organizations, Guzzo, R. \& Salas, E. (eds), pp. 46-78. Jossey-Bass Publishers, San Francisco.

Huber, G.P. (1990) A theory of the effects of advanced information technologies on organizational design, intel- ligence, and decision making. Academy of Management Review, 15, 47-71.

Huber, G.P. (1991) Organizational learning: The contributing processes and the literatures. Organizational Science, 2, 88-115.

Isenberg, D. (1986) Group polarization: a critical review and meta-analysis. Journal of Personality and Social Psychology, 49, 1141-1151.

Jackson, S.E., Stone, V.K. \& Alvarez, E.B. (1992) Socialization amidst diversity: The impact of demographics on work team old-timers and newcomers. In: Research in Organizational Behavior, vol. 15, Cummings, L. \& Staw, B. (eds), pp. 45-109. JAI Press, Greenwich, CT.

Janis, I.L. (1982) Groupthink. Houghton Mifflin, Boston. Jarvenpaa, S.L., Knoll, K. \& Leidner, D.E. (1998) Is anybody out there? Antecedents of trust in global virtual teams. Journal of Management Information Systems, 14, 29-64.

Kirkman, B.L. \& Shapiro, D.L. (1997) The impact of cultural values on employee resistance to teams: Toward a model of globalized self-managing work team effectiveness. Academy of Management Review, 22, 730-757.

Latane, B. (1986) Responsibility and effort in organizations. In: Designing Effective Work Groups, Goodman, P. (ed.), pp. 277-304. Jossey-Bass Publishers, San Francisco.

Latane, B., Williams, K. \& Harkins, S. (1979) Many hands make light the work: Causes and consequences of social loafing. Journal of Personality and Social Psychology, 37, 822-832.

Lawler, III, E.E. (1986) High-Involvement Management: Participative Strategies for Improving Organizational Effectiveness. Jossey-Bass Publishers, San Francisco.

Leonard-Barton, D. (1995) Wellsprings of Knowledge: Building and Sustaining the Sources of Innovation. Harvard Business School Press, Boston.

Lewis, R. (1998) Membership and management of a 'virtual' team: The perspectives of a research manager. $R$ and D Management , 28, 5-13.

Lipnack, J. \& Stamps, J. (1997) Virtual teams. In: Reaching Across Space, Time, and Organizations with Technology, John Wiley \& Sons, New York.

Locke, E., Shaw, K., Saari, L. \& Latham, G. (1981) Goalsetting and task performance. Psychological Bulletin, 90, 125-152.

Maples, M. (1988) Group development: Extending Tuckman's theory. Journal for Specialists in Group Work, Fall, pp. 17-23.

Markham, S. \& McKee, G. (1995) Group absence behavior and standards: a multi-level analysis. Academy of Management Journal, 38, 1174-1190. 
Mayer, R.C., Davis, J.H. \& Schoorman, F.D. (1995) An integrative model of organizational trust. Academy of Management Review, 20, 709-734.

McGrath, J.E. (1991) Time, interaction, and performance (TIP): a theory of groups. Small Group Research, 22, 147-174.

Mowery, D., Oxley, J. \& Silverman, B. (1996) Strategic alliances and interfirm knowledge transfer. Strategic Management Journal of Special Issue on Knowledge and the Firm, 17, 77-91.

Nemeth, C.J. (1993) Dissent, group process, and creativity. In: Social Psychology of Groups, a Reader, Lawler, E.J. \& Markovsky, B. (eds), pp. 107-126. Jossey-Bass Publishers, San Francisco.

Nonaka, I. (1991) The knowledge-creating company. Harvard Business Review, November-December, 96-104.

O'Hara-Devereaux, M. \& Johansen, R. (1994) GlobalWork: Bridging Distance, Culture, and Time. JosseyBass Publishers, San Francisco.

Paese, P., Bieser, M. \& Tubbs, M. (1993) Framing effects and choice shifts in group decision making. Organizational Behavior and Human Decision Processes, 52, 149-165.

Pritchard, R., Jones, S., Roth, P., Stuebing, K. \& Edeberg, S. (1988) Effects of group feedback, goal-setting, and incentives on organizational productivity. Journal of Applied Psychology Monograph, 73, 337-358.

Schnake, M.E. (1991) Equity in effort: The 'sucker effect' in co-acting groups. Journal of Management, 17, 41-55.

Senge, P. (1990) The Fifth Discipline. Currency-Doubleday Publishers, New York.

Siegel, J., Dubrovsky, V., Kiesler, S. \& McGuire, T.W. (1986) Group processes in computer-mediated communication. Organizational Behavior and Human Decision Processes, 37, 157-186.

Sproull, L. \& Kiesler, S. (1986) Reducing social context cues: Electronic mail in organization communication. Management Science, 32, 1492-1512.

Stevens, M.J. \& Campion, M.A. (1994) The knowledge, skill, and ability requirements for teamwork: Implications for human resource management. Journal of Management, 20, 503-530.
Sundstrom, E., DeMeuse, K.P. \& Futrell, D. (1990) Work teams: applications and effectiveness. American Psychologist, 45, 120-133.

Townsend, A.M., DeMarie, S.M. \& Hendrickson, A.R. (1998) Virtual teams: Technology and the workplace of the future. Academy of Management Executive, 12, 1729.

Tsui, A.S., Egan, T.D. \& O'Reilly, III, C.A. (1992) Being different: Relational demography and organizational attachment. Administrative Science Quarterly, 37, 549579.

Tuckman, B. (1965) Developmental sequences in small groups. Psychological Bulletin, 63, 384-399.

Tuckman, B. \& Jensen, M. (1977) Stages of small-group development rev isited. Group and Organization Studies, 2, 419-427.

Vroom, V. \& Yetton, P. (1973) Leadership and Decision Making. University of Pittsburgh Press, Pittsburgh.

Wagner, III, J.A. (1995) Studies of individualism-collectivism: Effects on cooperation in groups. Academy of Management Journal, 38, 152-172.

Walsh, J.P. \& Ungson, G.R. (1991) Organizational memory. Academy of Management Review, 16, 57-91.

Warkentin, M.E., Sayeed, L. \& Hightower, R. (1997) Virtual teams versus face-to-face teams: an exploratory study of a web-based conference system. Decision Sciences, 28 , 975-996.

Watson, W.E., Kuman, K. \& Michaelson, L. (1993) Cultural diversity's impact on interaction process and performance: Comparing homogeneous and diverse task groups. Academy of Management Journal, 36, 590-602.

Watson-Fritz, M.B., Narasimhan, S. \& Rhee, H. (1998) Communication and coordination in the virtual office. Journal of Management Information Systems, 14, 7-28.

Whyte, G. (1989) Groupthink reconsidered. Academy of Management Review, 14, 40-56.

Yamagishi, T. (1993) The structural goal/expectation theory of cooperation. In: Social Psychology of Groups: a Reader, Lawler, E.J. \& Markovsky, B. (eds), pp. 159192. Jossey-Bass Publishers, San Francisco. 
Copyright of Information Systems Journal is the property of Wiley-Blackwell and its content may not be copied or emailed to multiple sites or posted to a listserv without the copyright holder's express written permission. However, users may print, download, or email articles for individual use. 